\title{
ALGUNS APONTAMENTOS PARA UMA HISTÓRIA DA HIL NA FRANÇA E NO BRASIL
}

\author{
Thaís de Araujo da Costa*
}

UFF

Resumo: Este artigo tem por objetivo apresentar algumas considerações sobre o processo de institucionalização $e$ disciplinarização no Brasil e na França da História das Ideias Linguísticas (HIL), notadamente daquela que se desenvolve a partir da articulação com a Análise de Discurso de origem francesa (AD). Para tanto, buscar-se-á responder a três perguntas norteadoras: 1) em que consiste a articulação entre HIL e AD?; 2) como se constitui a relação entre o lugar do analista de discurso e o do historiador das ideias linguísticas; e 3) qual a diferença entre História das Ideias Linguísticas e Historiografia Linguística?

Abstract: This paper aims to present some considerations on the process of institutionalization and disciplinarization of the History of Linguistic Ideas (HIL) in Brazil and in France, especially the one emerging from the articulation with French Discourse Analysis (AD). To do so, three are the guiding questions to be answered: 1) what kind of articulation is held between HIL and AD?; 2) how is established the relationship between the position of the discourse analyst and the one of the historian of the linguistic ideas?; and 3) what is the difference between History of the Linguistic Ideas and Linguistic Historiography?

\section{Introdução}

Neste artigo, proponho-me a tecer algumas considerações a respeito do processo de institucionalização e disciplinarização da História das Ideias Linguísticas (HIL) no Brasil e na França, notadamente daquela que se desenvolve na relação com a Análise de Discurso $(A D)$, produzida a partir dos trabalhos de Michel Pêcheux, na França, e dos de Eni Orlandi, no Brasil. De início, faz-se preciso pontuar que, assim como Ferreira (2018), entendo que no Brasil:

\section{$(\mathrm{Cc}) \mathrm{BY}-\mathrm{NC}-\mathrm{SA}$}

Líng. e Instrum. Linguíst., Campinas, SP, n. 44, p.9-34, jul./dez. 2019 
o modo pelo qual a institucionalização das pesquisas em História das Ideias Linguísticas iniciou foi norteador para a maneira como esse nome - História das Ideias Linguísticas significa enquanto designação de um domínio de conhecimento, ao lado de outros nomes, notadamente, o nome Análise de Discurso (FERREIRA, 2018, p.17-18).

Desse modo, a singularidade do processo de historicização da HIL no Brasil, associada ao número reduzido de obras na literatura especializada que abordem de forma pormenorizada a temática aqui aventada, justifica a relevância deste e de outros trabalhos que se proponham a refletir sobre o processo de historicização desse domínio de saber em solo brasileiro.

Devo alertar, contudo, que, também em virtude dessa falta, é possível que o leitor reconheça neste artigo um certo caráter tateante que o aproximaria de um ensaio. Mais do que escrever a história desse domínio, embora contribuir para esse fim seja o principal propósito desta reflexão, irei deter-me aqui a expor o gesto de leitura por mim depreendido quando, durante a escrita da minha tese de doutoramento $^{2}$, algumas questões se impuseram de tal forma que refletir acerca do fazer em HIL no Brasil tornou-se incontornável. Seguir esse trajeto tão pessoal de leitura é, pois, o que justifica o emprego por vezes da primeira pessoa do singular, reforçando o tom ensaístico do texto.

$\mathrm{Na}$ referida tese, inscrevendo-me no lugar de articulação entre $\mathrm{AD}$ e HIL, investiguei o funcionamento do discurso gramatical em circulação no Brasil no século XX. De início, o significante "articulação", tão presente nos trabalhos filiados à mesma perspectiva teórica que a minha, me causava um certo incômodo devido à sua opacidade. De fato, o que se diz quando se afirma que há uma articulação entre um domínio e outro? Ou em outras palavras, em que consiste essa articulação a partir da qual inclusive desenvolvo as reflexões ora apresentadas?

Somou-se a essa questão, à época, ainda uma outra - decorrente de uma aparente superposição entre o objeto de análise, o aporte teórico adotado e os lugares em que eu me inscrevia enquanto professora de língua portuguesa e pesquisadora que ia se constituindo como tal e como autora a partir desse lugar de teorização -: afinal, eu era uma 
historiadora que fazia análise do discurso gramatical ou uma analista de discurso que tinha como objeto a história das ideias linguísticogramaticais (re)produzidas no Brasil num determinado período? ${ }^{3} \mathrm{Ou}$ seja, embora nesse momento eu ainda não soubesse, a questão que então se colocava era compreender como se constitui discursivamente a relação entre esses dois lugares: o do analista e o do historiador - e como essa relação não só me afeta enquanto sujeito-pesquisadora, mas, consequentemente, como afeta o meu objeto, o meu fazer analítico e o processo de escrita resultante desse fazer.

Note-se, portanto, que responder a essas questões era crucial não só para depreender o funcionamento das contradições constitutivas da institucionalização desses domínios no Brasil em seus modos de articulação ${ }^{4}$, como para, enfim, dar início à análise da materialidade das gramáticas e à escrita da tese. Porém, antes de compreender como enquanto sujeito-pesquisadora eu era afetada e em que lugar, nessa articulação, eu me inscrevia, fez-se necessário, considerando, como pontua Pêcheux (2006, p.18), que a simples menção dos nomes desses domínios de saber não é "suficiente para caracterizar uma posição de trabalho", refletir sobre o processo de constituição por que passou cada um em solo brasileiro e os (des)limites que se colocaram como efeito desse encontro.

Assim sendo, cabe, por fim, esclarecer que, apesar de a reflexão que aqui tecerei ter como escopo iluminar alguns aspectos do processo histórico por meio do qual a HIL se estabeleceu no Brasil, ao longo da análise, devido ao percurso traçado nesse processo, por vezes será evocado o cenário europeu, bem como o encontro entre a HIL e outras disciplinas em solo francês e brasileiro. Além disso, farei também alguns apontamentos a respeito da relação estabelecida entre HIL e Historiografia Linguística (HL) na Europa e no Brasil.

\section{Processo de institucionalização e disciplinarização da HIL no Brasil}

Essa história começa nos anos 1980. Após um processo de institucionalização e de disciplinarização iniciado na década anterior (Scherer; Sousa; Medeiros; Petri, 2014), ganhava visibilidade nas universidades brasileiras, sobretudo com os trabalhos de Eni Orlandi, professora do Instituto de Estudos da Linguagem da Universidade Estadual de Campinas (IEL/Unicamp), a AD formulada, na França, na 
década de 1960, por Michel Pêcheux e o grupo de pesquisadores que com ele trabalhava. A AD pecheutiana ou francesa, como ficou conhecida, havia nascido a partir da articulação e do deslocamento de três regiões do conhecimento científico - linguística, materialismo histórico e teoria do discurso - e da consideração do atravessamento dessas regiões por uma teoria da subjetividade (de natureza psicanalítica) (Pêcheux; Fuchs, [1975] 2010) ${ }^{5}$ - articulação esta que, a despeito das contribuições teóricas efetuadas pelos pesquisadores brasileiros, aqui se manteve e se mantém até os dias atuais.

Nessa mesma década, um projeto coletivo intitulado "Discurso, Significação, Brasilidade" era desenvolvido na Unicamp sob a coordenação de Eni Orlandi. Incluindo como uma de suas linhas de pesquisa a questão da língua e da brasilidade, foram nessa época desenvolvidos no cerne desse projeto estudos sobre a história da língua portuguesa no/do Brasil na sua relação com as línguas indígenas e com as línguas de imigração aqui faladas.

Embora se possa afirmar que o germe do encontro entre HIL e AD está nessas pesquisas, é somente na década de 1990 que esse encontro ganha forma material, notadamente a partir do estabelecimento de um projeto de colaboração científica franco-brasileiro liderado por Eni Orlandi e Sylvain Auroux, membro do Laboratoire d'Histoire des Théories Linguistiques (LAB-HTL)/ Paris $7^{6}$, centro de irradiação na Europa dos estudos em HIL do qual o pesquisador francês viria a ser diretor de 1992 a 2001. Auroux à época se encontrava à frente de um grande projeto coletivo e internacional, iniciado em 1982, que, sob o título "Histoire des idées linguistiques", tinha por objetivo promover uma revisão das pesquisas consagradas a esse tema ${ }^{7}$. Já Eni Orlandi realizava, nos anos 1987-1988, um estágio de pós-doutorado na França quando tomou conhecimento do projeto organizado por Auroux. A partir desse contato inicial, foi assinado, no ano seguinte, um convênio entre a Unicamp e a Universidade de Paris VII e, em 1992, o projeto de colaboração científica franco-brasileiro, intitulado "História das Ideias Lingüísticas: Construção do Saber Metalinguístico e a Constituição da Língua Nacional”, que, contando com a participação de pesquisadores franceses e brasileiros filiados a lugares teóricos diversos, tinha por objetivo estender as reflexões em história das ideias linguísticas que já vinham sendo desenvolvidas na Europa aos países ditos de colonização, tornando possível pensar a 
história da constituição do saber linguístico e metalinguístico sobre a língua no/do Brasil, na sua relação com a constituição dessa língua como língua nacional (Orlandi, 2001) ${ }^{8}$.

Posteriormente, mais especificamente entre 1996 e 2003, um outro projeto, nomeado "História das Ideias Linguísticas no Brasil: Ética e Política de Línguas", a partir do qual se buscou pensar a questão das relações de línguas como uma questão política, incluiu, no Brasil, na coordenação, ao lado de Eni Orlandi, Diana Luz Pessoa de Barros, professora especializada em Semiótica Discursiva da Universidade de São Paulo (USP), e, na França, pesquisadores da École Normale Supérieure Fontenay/Saint-Cloud, hoje École Normale Supérieure de Lettres et Sciences Humaines, em Lyon. Filiados a esse projeto, foram desenvolvidos ainda diversos trabalhos em outras universidades brasileiras para além da Unicamp e da USP e europeias, como a Université de Lausanne, na Suíça, e a Université Sorbonne Nouvelle, na França, e estabelecidos contatos menos formalizados com pesquisadores de universidades da Alemanha e da Itália ${ }^{910}$. Entre os anos de 2005-2008, um terceiro grande projeto intitulado "O Controle Político da Representação: Uma História das Ideias” foi desenvolvido sob a coordenação de Eduardo Guimarães (Unicamp), no Brasil, e Jean-Claude Zancarini (ENSLSH), na França.

Ferreira (2018) cita como responsáveis pela expansão dos estudos em HIL no Brasil, paralelamente a esse acordo de cooperação internacional: 1) o estabelecimento de acordos interinstitucionais nacionais realizados no início dos anos 2000, os quais proporcionaram o desenvolvimento de vários outros projetos; 2) a institucionalização de linhas de pesquisa e de disciplinas em HIL ou que levam em conta esse campo de pesquisa, o que resultou numa grande quantidade de dissertações e teses defendidas nessa área ou a ela articulada, muitas das quais inclusive tornaram-se posteriormente livros; 3) a realização de eventos científicos específicos ou com relevante participação de pesquisadores dessa área; e 4) a publicação de periódicos especializados, como a Revista Língua e Instrumentos Linguísticos, em circulação desde 1998; ou com edições voltadas especificamente para essa área, como o número 52 e o número Especial da Revista Fragmentum, de 2018; o número 42 da revista Letras, de 2011, e o número 42 da revista Cadernos de Estudos Linguísticos, de 2002.

A partir desse breve panorama histórico, devemos fazer aqui 
algumas considerações. A primeira diz respeito à transferência tanto da $\mathrm{AD}$ quanto da HIL da França para o Brasil, processo este ao qual, como podemos depreender a partir de Orlandi (2003) ${ }^{11}$, essas teorias não passam incólumes. $\mathrm{E}$ isso porque, como explica a autora, a transferência pressupõe o trabalho da memória local, que promoveu, nesse caso especificamente, em função das distintas condições de produção, alguns deslocamentos necessários para que essas teorias se desenvolvessem e conquistassem espaço nas universidades brasileiras. Isso significa, em outras palavras, que, uma vez em solo nacional, tanto a $\mathrm{AD}$ quanto a HIL já não poderiam mais ser as mesmas de alhures, ou melhor, são as mesmas, porque nelas há algo que permanece das teorias europeias, mas também são outras, com peculiaridades inerentes às novas condições de produção em que se inscrevem, porque são frutos de deslizamentos historicizados de sentidos, os quais também produzem efeitos sobre esse lugar que se disse ser de articulação entre AD e HIL.

Um outro ponto a que devemos nos deter aqui diz respeito à heterogeneidade constitutiva do processo de institucionalização e disciplinarização da HIL em terras brasileiras. Como dito anteriormente, a HIL foi introduzida em nossas universidades por meio do estabelecimento de projetos de colaboração científica francobrasileiro. Sobre a equipe de pesquisadores filiados a esses projetos, afirma Ferreira (2018):

Se, de um lado, os primeiros projetos de História das Ideias Linguísticas se produziram a partir de uma articulação forte com a Análise de Discurso, de outro, eles também puderam integrar pesquisadores de diversas instituições universitárias brasileiras, inscritos em áreas diferentes, como, por exemplo: sintaxe, semântica, análise de discurso, semiótica, pragmática, sociolinguística, linguística indígena, lexicologia, filosofia da linguagem, história, estudos clássicos, ciências da informação e da cognição e literatura (FERREIRA, 2018, p.20).

Do inserto, podemos concluir que, embora sejam significados no currículo de alguns programas de pós-graduação, como, por exemplo, o da Unicamp e o da UFF, não só como disciplina autônoma, mas também como linha de pesquisa, muitas vezes os estudos em HIL são 
desenvolvidos no Brasil a partir de articulações com outros lugares teóricos. Dessas articulações, dadas as ressonâncias produzidas de um domínio em outro, emergem distintos fazeres teórico-analíticos. Daí as considerarmos como (des)encontros, na medida em que o encontro de uma teoria com uma outra teoria produz o desencontro dessas teorias com elas mesmas. Podemos citar como exemplo disso que está sendo colocado, além da articulação entre HIL e Semiótica Discursiva e entre aquela e $\mathrm{AD}$, cujos nomes de referência no Brasil, como visto, são, respectivamente, Diana Luz Pessoa de Barros e Eni Orlandi ${ }^{12}$, a articulação entre HIL e Semântica Enunciativa, que tem como nome de referência o do professor Eduardo Guimarães (Unicamp).

Além da heterogeneidade constitutiva decorrente desses distintos (des)encontros, são desenvolvidos também no Brasil, ao lado das reflexões em HIL, estudos que se inscrevem no lugar teórico da chamada Historiografia Linguística (HL), cujos nomes de referência são Cristina Altman (2012), no Brasil, notadamente no Centro de Documentação em Historiografia Linguística (CEDOCH-DL/USP) ${ }^{13}$, Konrad Koerner (1978/1996/2014) e Pierre Swiggers (1996/2010), na Europa.

\section{Qual a diferença entre História das Ideias Linguísticas (HIL) e Historiografia Linguística (HL)?}

Essa foi uma das perguntas que se impuseram a mim ao cursar, durante o meu estágio doutoral na Université Sorbonne Nouvelle, no segundo semestre de 2015, a disciplina História das Ideias Linguísticas. Lembremos aqui que, como dito anteriormente, eu havia ido para o estágio sem saber ainda se era uma historiadora que fazia análise do discurso gramatical ou uma analista de discurso que tinha como objeto a história das ideias linguístico-gramaticais. Ocorre que, no semestre anterior, eu havia cursado uma disciplina de Historiografia Linguística, no Brasil, e quanto mais eu mergulhava no estudo da HIL, mais opaca parecia para mim a distinção entre esta e aquela, sobretudo porque, nas aulas na França, percebi que a distinção entre um domínio e outro não era uma questão que se colocasse. Nesta seção, então, levantarei pontos que, a meu ver, produzem essa opacidade para então defender a tese de que há, na Europa, uma contradição constitutiva entre esses dois domínios, HIL e HL, que não se coloca da mesma forma no Brasil, pelo menos não no que concerne 
à relação entre o fazer teórico-metodológico da HL e o resultante da articulação AD-HIL.

Em primeiro lugar, o que chamou a minha atenção foi o fato de que tanto os estudos de Konrad Koerner quanto os de Pierre Swiggers são citados indistintamente por pesquisadores filiados ao LAB-HTL na França, assim como os de Auroux e de outros teóricos desse laboratório o são pelos estudiosos de HL no Brasil e na Europa. Além disso, lendo as obras de referência desses domínios, é possível observar diversos pontos de encontro, o que nos sugere a existência de uma tensão constitutiva entre esses domínios, bem como entre as práticas a eles filiadas e entre os sentidos de história e historiografia colocados em funcionamento, como ilustra o quadro a seguir:

\begin{tabular}{|c|c|}
\hline \multicolumn{2}{|c|}{ Quadro 1 - HIL X HL } \\
\hline HIL & HL \\
\hline 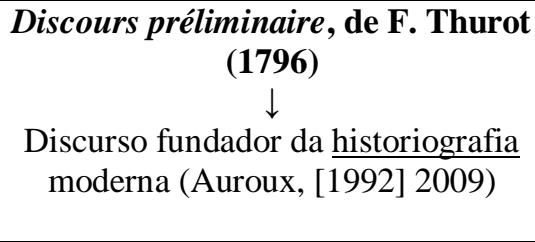 & 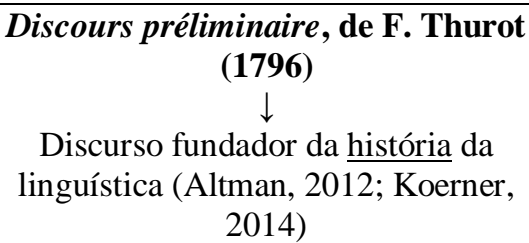 \\
\hline $\begin{array}{c}\text { F. Thurot } \\
\downarrow \\
\text { primeiro historiador da gramática } \\
\frac{(\text { Auroux, ibid.) }}{}\end{array}$ & $\begin{array}{c}\text { F. Thurot } \\
\downarrow \\
\text { primeiro historiógrafo da linguística } \\
\text { (Swiggers, 1996; Koerner, 1978; } \\
\text { Altman, 2012) }\end{array}$ \\
\hline $\begin{array}{c}\text { Historiographia Linguistica } \\
\text { fundada por Koerner em } 1974 \\
\downarrow \\
\text { a primeira publicação especializada } \\
\text { da área (Auroux, 1988) }\end{array}$ & $\begin{array}{c}\text { Historiographia Linguistica } \\
\text { fundada por Koerner em } 1974 \\
\downarrow \\
\text { a primeira publicação especializada } \\
\text { da área (Altman, ibid.) } \\
\end{array}$ \\
\hline
\end{tabular}

Como é possível ler no Quadro 1, nesses dois lugares, o Discours préliminaire, de F. Thurot, publicado em 1796, é significado como 
discurso fundador ${ }^{14}$ da "historiografia moderna" por Auroux ([1992] 2009, p.11) e da história da linguística por Koerner (2014) e Altman (2012). Em função dessa publicação, Thurot também é significado como o primeiro "historiador da gramática" por Auroux (ibid.) e como o primeiro "historiógrafo da linguística" por Koerner (1978), Swiggers (1996) e, à luz desses e outros autores, por Altman (ibid.). Além disso, também de ambos os lugares, a revista internacional Historiographia Linguistica, fundada por Koerner em 1974, é tomada como a primeira publicação especializada da área (Auroux, 1988; Altman, 2012; Koerner, 2014).

No tocante aos conceitos e à relação estabelecida entre história e historiografia, observa-se que há nas obras de referência de ambos os domínios um movimento de distinção de um fazer caracterizado, no âmbito da HL, como história da linguística e, no da HIL, como historiografia moderna. Lemos em Koerner (1996, p.25) que a historiografia diz respeito a um "modo de escrever a história do estudo da linguagem" que tem como resultado "a história, i.e., o discurso do passado tal como produzido pelo historiador" (ibid., p.26). Altman (2012), à luz das reflexões de Koerner, elenca diferentes práticas historiográficas desenvolvidas desde o século XVIII, produzindo um efeito de distinção entre os estudos filiados ao que chama de história da linguística, a qual é predicada pela autora como "tradicional" e na qual, segundo ela, se observa de modo geral o estabelecimento "da figura individual do autor da teoria, do precursor genial, do pioneiro na aplicação de um método ou na construção de um modelo" (ibid., p.23), e os que se inscrevem em HL, os quais, não se resumindo como aqueles a "crônicas", isto é, "a uma simples compilação de datas, fatos, títulos e nomes relacionados com o estudo das línguas e da linguagem" (ibid., p.26), têm por objetivo "compreender os movimentos em história da ciência" a partir de "uma atividade de seleção, reconstrução, ordenação e interpretação dos fatos" (ibid., p.27, itálico nosso).

Já Auroux ([1992] 2009) propõe, relendo Koerner (1978), a divisão dos trabalhos consagrados à história dos conhecimentos linguísticos a partir do século XIX, retomada, em nota, como "historiografia moderna" (ibid., p.11, nota 1), em três categorias: 1) os que, de base documentária e factual, têm por objetivo reunir documentos referentes ao conhecimento e à história das línguas; 2) os que, também de base 
factual, são homogêneos à prática de que derivam, como, por exemplo, os estudos desenvolvidos por filólogos sobre a gramática; e 3) os que, de papel fundador, voltam-se sobre o passado com vistas a legitimar uma prática contemporânea ${ }^{15}$. O autor acrescenta ainda uma quarta categoria que é constituída por obras de orientação generalizante $^{16}$ que, surgidas a partir de meados do século $X X$, se propunham a "fazer a história da linguística concebida como uma ciência, isto é, como uma forma de saber cuja organização e cujas propriedades formais seriam estáveis" (ibid., p.12, itálico nosso). Note-se aqui que essas quatro categorias elencadas por Auroux muito se aproximam do que Koerner (2014) e Altman (2012) designam como história da linguística, de cujo fazer teórico-metodológico, conforme os autores, distingue-se o da HL.

Do lugar da HIL, distanciar-se do conceito de ciência pressuposto na quarta categoria elencada por Auroux é o que justifica a proposta de substituição do significante teorias - presente na designação do laboratório francês, por exemplo - por ideias - nome pelo qual atualmente é designada a teoria, embora na França ainda compareça, ao lado desse, o nome História das Teorias Linguísticas. Como explicam Colombat, Fournier e Puech (2010), a noção de teoria poderia colocar em questão uma certa concepção de ciência desenvolvida no ocidente a partir do século XVIII, sendo, desse modo, mais adequado empregar o termo ideias por este ter a vantagem de ser menos engajado epistemologicamente ou, em outras palavras, de apresentar um engajamento menos normativo levando em consideração a diversidade de formas que o saber pode tomar na história.

Essa substituição produz ainda, a nosso ver, um efeito de distanciamento entre o fazer em HIL, tal como formulado na França, e o fazer em HL, cuja filiação produz sentidos no Brasil, já que por Historiografia Linguística entende-se, como podemos deduzir a partir de Koerner (1996) e Altman (2012), a escrita da história da (ciência) linguística ou (das ciências) da linguagem. Diz Altman (2012):

A historiografia linguística que ambicionar descrever e explicar a história das ciências da linguagem, e os fatores que puderem ser associados ao seu desenvolvimento, deve ambicionar igualmente examinar as circunstâncias de produção e de 
recepção do conhecimento que se constrói sobre a linguagem e as línguas. Dessa perspectiva, a historiografia linguística tem como objeto a história dos processos de produção e de recepção das ideias linguísticas e das práticas delas decorrentes que, por sua vez, geraram novas ideias e novas práticas, em um processo de continuidade e descontinuidade, de avanços e de retomadas, inerentes à busca de conhecimento (ALTMAN, 2012, p.22, sublinhados nossos).

Observemos aqui que a expressão ideias linguísticas, em Altman (ibid.), tem um sentido distinto daquele que comparece em Colombat, Fournier e Puech (2010), visto que se filia tão somente ao que, desse lugar, se toma por conhecimento científico, e se distanciar dessa concepção de ciência, como vimos, é justamente o que justifica a substituição de teorias por ideias na designação do domínio de saber.

A tensão entre os sentidos de história e historiografia, bem como a heterogeneidade constitutiva das práticas filiadas a esses nomes, se faz significar em diversos estudos do domínio da HIL. Dentre esses, destacamos o artigo Histoire des idées linguistiques et Horizons de rétrospection, de Christian Puech (2006), membro e ex-diretor adjunto do LAB-HTL. Segundo esse autor, nos anos 1950 e 1960, o fazer historiográfico estava associado a abordagens simplificadoras (nas quais predominavam noções como a de "influência" e "precursor", periodizações aproximativas e uma teologia positivista), advindas, sobretudo, do empréstimo da noção de paradigma de Thomas Kuhn.

É necessário aqui fazermos uma breve digressão para que compreendamos o posicionamento de Puech (ibid.). Para Kuhn ([1962-1970] 1983), uma disciplina se torna ciência quando adquire um paradigma, isto é, um modelo a partir do qual se estruturam tradições particulares e coerentes de prática científica. Para tanto, é preciso que haja duas características essenciais simultâneas: suas realizações devem ser suficientes para atrair um grupo de adeptos, afastando-os de outras formas de atividades científicas concorrentes, e devem abrir perspectivas suficientemente vastas para fornecer a esse novo grupo de pesquisadores todo tipo de problemas a serem resolvidos. Quando um paradigma, após inúmeras tentativas dos pesquisadores, mostra-se insuficiente para resolver um problema, instala-se o que Kuhn denominou como situação de crise, a partir da 
qual paradigmas alternativos começam a ser propostos e discutidos pela comunidade científica até que o paradigma anterior seja, por fim, substituído por um novo paradigma que se mostra superior a ele em todos ou quase todos os aspectos. A essa substituição Kuhn chama Revolução científica. A partir dela, muitas práticas do paradigma anterior assumem uma relação que não tinham antes, e outras tornamse irrelevantes, sendo substituídas por novas práticas. Trata-se, pois, para o autor, de "un déplacement du réseau conceptuel à travers lequel les hommes de science voient le monde" (ibid., p.147) ${ }^{17}$.

A crítica de Puech (2006) reside, então, no fato de muitos manuais de linguística adotarem a noção de paradigma e determinarem um linguista como o precursor da ciência, seja ele Bopp, Saussure ou Chomsky, rejeitando tudo o que vem antes desse 'marco' por considerarem como não ciência. Essa seria, pois, uma distinção crucial entre o fazer em HIL e o fazer em HL. Além disso, tal perspectiva não leva em consideração, na produção histórica do conhecimento, o que Colombat, Fournier e Puech (2010) designam como processo de cumulação. A questão da cumulação, segundo os autores, é uma questão central na história das ciências, embora muitas disciplinas possam ser menos cumulativas, ou melhor, possam não revelar o processo de cumulação pelo qual elas se constituem historicamente. No que diz respeito especificamente aos saberes sobre a língua e sobre a linguagem, os autores afirmam que o fato de serem necessariamente construções históricas de longa duração implica uma certa forma de cumulação de conhecimentos nas suas disciplinas (como a gramática, a retórica...). Essa memória cumulativa, no entanto, tem furos, visto que, ao lado da suposta transmissão de uns conceitos, há, ao mesmo tempo, o esquecimento de outros, cabendo ao historiador, considerando essa característica, "créer également les conditions d'une réflexion de fond sur le mode d'être particulier des connaissances dans les sciences du langage, à savoir qu'elles peuvent être l'objet contradictoirement d'oubli ou de la cumulation" (ibid., p. 12$)^{18}$.

A partir dessa perspectiva, Puech (2006) afirma, então, que o desenvolvimento das pesquisas em historiografia acarretou, à medida que houve o distanciamento da proposta kuhniana, a emergência de "modèles historiographiques plus ou moins complémentaires ou plus ou moins concurrentiels" (ibid., p.13) ${ }^{19}$, sobre os quais os estudiosos 
se voltaram a partir dos anos 1990, colocando em questão o que desde então se tem proposto chamar de meta-historiografia. Visando historicizar esses distintos fazeres, Puech (ibid.) elenca diferentes sentidos para os termos história e historiografia que se encontram em circulação nas reflexões sobre a história dos estudos da linguagem. Tais sentidos convivem, disputam espaço, se cruzam e se entrecruzam na França pelo menos desde o final do século XX, passam a se relacionar com o sentido de meta-historiografia, como vimos, a partir da década de 1990 e também se fazem significar de certo modo nas práticas desenvolvidas no Brasil. $\mathrm{O}$ quadro a seguir faz uma síntese dos sentidos que comparecem em Puech (ibid.), buscando relacionálos ao que foi dito até o momento neste artigo. Vejamos:

\begin{tabular}{|c|c|c|c|}
\hline \multicolumn{4}{|c|}{ Quadro 2 - história, historiografia e meta-historiografia (Puech, 2006) } \\
\hline Sentidos para história & \multicolumn{3}{|c|}{$\begin{array}{c}\text { Relação com história, historiografia, meta- } \\
\text { historiografia }\end{array}$} \\
\hline $\begin{array}{l}\text { 1) a história de um } \\
\text { personagem, uma pura e } \\
\text { simples cronologia de } \\
\text { eventos, processos e fatos } \\
\text { registrados pelo } \\
\text { historiógrafo num arquivo } \\
\text { documentário; }\end{array}$ & \multirow{4}{*}{$\begin{array}{c}\text { Referem-se a } \\
\text { diferentes práticas } \\
\text { (não excludentes) } \\
\text { consideradas } \\
\text { historiográficas }\end{array}$} & \multicolumn{2}{|c|}{$\begin{array}{c}\text { Historiografia } \\
\text { documental } \\
\text { *Historiografia moderna } \\
\text { (Auroux, 2009) } \\
\text { *História da linguística } \\
\text { (Altman, 2012; Koerner, } \\
\text { 2014) }\end{array}$} \\
\hline $\begin{array}{l}\text { 2) complexo de eventos, } \\
\text { processos, fatos...; }\end{array}$ & & $\begin{array}{l}\text { Prática de } \\
\text { escrita (a }\end{array}$ & Objeto \\
\hline \multirow[t]{2}{*}{$\begin{array}{l}\text { 3) o resultado da análise } \\
\text { historiográfica; }\end{array}$} & & $\begin{array}{l}\text { partir de um } \\
\text { determinado } \\
\text { método) da } \\
\text { história } \\
\end{array}$ & Produto \\
\hline & & \multicolumn{2}{|c|}{$\begin{array}{c}\text { Objeto da } \\
\text { Meta-historiografia }\end{array}$} \\
\hline $\begin{array}{l}\text { 4) historicidade, no sentido } \\
\text { em que as ideias } \\
\text { linguísticas não são } \\
\text { somente produzidas no } \\
\text { tempo, mas também }\end{array}$ & \multicolumn{3}{|c|}{$\begin{array}{l}\text { Referem-se à singularidade do domínio da } \\
\text { HIL, tal como formulada e desenvolvida na } \\
\text { França }\end{array}$} \\
\hline
\end{tabular}


produzem a sua própria temporalidade; e

5) enquanto história dos estudos linguísticos, como uma epistemologia histórica, isto é, como a história da produção do conhecimento linguístico.

Como podemos ler no Quadro 2, Puech (ibid.) apresenta cinco sentidos para o termo história. Em relação ao quinto sentido, faz-se preciso observar a citação não marcada de Auroux ([1992] 2009) para quem o fazer histórico que dá nome à teoria (História das Ideias Linguísticas) está associado a uma prática epistemológica, já que esse autor propõe que seja feita pelo historiador das ideias linguísticas uma epistemologia histórica. Voltaremos a esse ponto adiante.

Desse modo, enquanto os sentidos 4) e 5) filiam-se, em Puech (2006), ao domínio da HIL, os sentidos 1), 2) e 3) colocam em questão diferentes práticas ditas historiográficas, a saber: documentação histórica em 1) e prática de escrita (a partir de um determinado método) da história em 2) e 3), com a diferença de que em 2) temos o objeto dessa prática e em 3) o seu produto. A este último sentido se filia, ainda, conforme o autor, o de meta-historiografia, tomada como reflexão metodológica e epistemológica sobre os modelos historiográficos adotados pelos historiadores (e não pelos historiógrafos $)^{20}$, o que significa dizer que ao sentido de historiografia enquanto prática de escrita - sentido este que já havíamos visto em Koerner (1996) - filiam-se também os estudiosos inscritos no domínio da HIL.

Por fim, observemos aqui as relações que podem ser estabelecidas entre as propostas de Puech (ibid.), Auroux (2009), Altman (2012) e Koerner (2014). O que o primeiro caracterizou como uma historiografia documental é significado pelo segundo como historiografia moderna e pelos dois últimos como história da linguística. A tensão entre esses significantes (história, historiografia) e - por conseguinte - entre os sentidos a eles atribuídos materializa a contradição existente entre esses dois domínios, contradição esta que se funda num movimento de deriva, de aproximar-se e afastar-se um 
do outro, conforme demonstram os textos aqui analisados.

Como vimos, a relação na França entre HIL e HL não é clara e muitas vezes os termos história e historiografia são empregados como sinônimos. A posição mais comumente adotada pelos pesquisadores de HIL nos dias atuais sobre a relação entre esses dois termos é a de que os fatos e as datas são históricos, o método que o historiador emprega para contá-los é historiográfico, e o relato do historiador a partir desse método historiográfico é o que se chama história. Notemos que, como visto, esse sentido de historiografia enquanto método a partir do qual se dá a escrita da história é o mesmo empregado pelos pesquisadores de HL, na Europa e no Brasil.

A naturalização desses sentidos de história e de historiografia, no âmbito dos trabalhos produzidos em HIL na França, tem como efeito o apagamento da distinção entre os dois domínios de saber, de modo que esta não seja mais uma questão que se coloque hoje. Apesar disso, como buscamos demonstrar, esses termos ainda concretizam uma contradição no que diz respeito à nomeação das práticas científicas desenvolvidas pela escola francesa, chamada História das Teorias Linguísticas ou História das Ideias Linguísticas, e pela escola anglosaxã, chamada Historiografia Linguística ou Gramaticografia, que se faz significar nos nomes pelos quais são designados os dois domínios.

Conforme dito anteriormente, a reivindicação do termo história, em vez de historiografia, por Auroux, mas antes dele por Jean-Claude Chevalier, fundador do LAB-HTL, está relacionada, sobretudo a partir dos trabalhos desenvolvidos pelo primeiro, a uma prática epistemológica. A concepção do fazer em HIL enquanto uma epistemologia histórica (Auroux, [1972] 2009) justifica ainda a proposta posterior de substituição do termo teorias por ideias, na nomeação desse domínio, já que pressupõe uma reflexão geral sobre as diferentes etapas do conhecimento humano sobre a língua/linguagem, e não somente ao que se tem por conhecimento científico, como sugerem os nomes Historiografia Linguística (escrita da história da Linguística) e Gramaticografia (escrita da Gramática). Note-se aqui ainda que essa busca pelo significante perfeito para nomear a prática dos pesquisadores filiados ao LAB-HTL está relacionada ao desejo de especificação da prática desenvolvida desse lugar e de imposição de limites em relação a outros lugares. A nomeação, conforme Mariani (1998), constitui-se como "um modo de 
construção discursiva de "referentes"” que se caracteriza por sua

capacidade de condensar em um substantivo, ou em um conjunto parafrástico de sintagmas nominais e expressões, 'os pontos de estabilização de processos' resultantes das relações de força entre formações discursivas concorrentes num mesmo campo (MARIANI, 1998, p.118).

Ou seja, uma vez que o nomear impõe o um, o mesmo, tem-se como efeito a naturalização e estabilização de sentidos, o que faz com que sejam promovidos os evidenciamentos e silenciamentos mencionados anteriormente. Apesar dessa força univocizante, contudo, como visto, a contradição entre esses dois domínios irrompe na língua, fazendo-se significar.

\section{Em solo brasileiro... a materialidade do (des)encontro entre AD e HIL e a resposta às minhas questões}

Diante da contradição entre HIL e HL observada nos estudos europeus, fez-se necessário voltar sobre os estudos desenvolvidos em solo brasileiro a fim de verificar a persistência e/ou ressonâncias produzidas. Antes, porém, deve-se esclarecer que a tensão vista na seção anterior entre os nomes história e historiografia e, consequentemente, entre as práticas que a eles se filiam é concebida nesta reflexão como uma heterogeneidade constitutiva desses domínios que está presente desde o seu momento de fundação, produzindo efeitos nos trabalhos desenvolvidos na Europa não só no modo como, desses lugares, o objeto é tomado, mas também na própria constituição desse objeto, isto é, na forma como ele é significado, a partir das diferentes perspectivas históricas/historiográficas.

Com a transferência da HIL para o Brasil, em função das articulações teóricas que mencionamos anteriormente, essa heterogeneidade ganha, como vimos na seção 1, novos contornos, novos (des)limites. Sendo assim, embora, como dissemos, a tensão entre história e historiografia não se coloque como na França, nos parece mais adequado falarmos, no que tange aos fazeres em HIL do Brasil $^{21}$, tendo em vista as diferentes articulações aqui estabelecidas, em Histórias das Ideias Linguísticas - com o núcleo do sintagma no 
plural -, das quais se distingue como uma disciplina outra a chamada Historiografia Linguística.

No que diz respeito particularmente ao (des)encontro com a Análise de Discurso, entendemos que, conforme Horta Nunes (2008, p.109), a articulação entre esses dois domínios de saber se funda numa "visão histórica da ciência e, particularmente, do que chamamos "ciências da linguagem'", compartilhada por ambos, ainda que se distinga o que se entende por história de cada um desses lugares, de maneira que um coloca questões ao outro, promovendo "ressonâncias tanto em uma quanto em outra direção". Nesse sentido, fazer História das Ideias Linguísticas do lugar da Análise de Discurso significa a possibilidade de tomar "diversas formas de discursos sobre a(s) língua(s) para análise", produzindo "leituras que remetem esses discursos às suas condições de produção". Para a depreensão dessas leituras, levam-se em consideração as materialidades linguísticas nas quais são produzidos, tomando-as não como "documentos transparentes ou simplesmente como antecessores ou percursores da ciência moderna", mas como "modos específicos de se produzir conhecimento em determinadas conjunturas históricas" (ibid., p.110).

Isso não significa, porém, que os conceitos operacionalizados em uma teoria e em outra são intercambiáveis. Vejamos, a título de exemplo, o conceito de gramática desenvolvido por Auroux ([1992] 2009). Segundo esse autor, "todo conhecimento é uma realidade histórica", isto é, todo "saber possui, por definição, uma espessura temporal" (ibid., p.12), que se volta para o passado (horizonte de retrospecção), ao mesmo tempo em que se projeta para o futuro (horizonte de projeção), já que, como esclarece o autor, "sem memória e sem projeto, simplesmente não há saber" (ibid., loc. cit.). A gramática é, pois, sob essa perspectiva, uma forma de saber, um produto histórico, cuja constituição no Ocidente remonta a Antiguidade Clássica e que hoje se distingue de outras formas de saber como, por exemplo, a linguística, tal como formulada a partir do século XX.

Em sua reflexão, o autor caracteriza ainda as gramáticas, ao lado dos dicionários, como instrumentos linguísticos, isto é, objetos técnicos investidos "necessariamente de conhecimentos teóricos explícitos" (ibid., p.70), cujo processo de produção, denominado gramatização, tem seu ponto de inflexão a partir do Renascimento 
europeu, quando se começou de forma massiva a descrever e a instrumentar todas as línguas do mundo, modificando-se, com isso, "profundamente a ecologia da comunicação humana" (ibid., p.9).

No que diz respeito especificamente às gramáticas, de acordo com Auroux, nelas se projeta uma hiperlíngua, isto é, um "sistema dinâmico" estruturado num determinado espaço/tempo, que "modifica e/ou prolonga a aptidão linguística de um indivíduo" (ibid., p.128). Nesse sentido, a gramática constitui-se como um instrumento porque, tal como um "martelo prolonga o gesto da mão, transformando-o", ela, ainda que de forma mais complexa, "prolonga a fala natural", dando "acesso a um corpo de regras e de formas que não figuram juntas na competência de um mesmo locutor" (ibid., p.70).

A partir da reflexão de Auroux, podemos depreender dois conceitos de gramática: o primeiro, a gramática enquanto forma de saber; e o segundo, a gramática enquanto instrumento linguístico. Esses conceitos, porém, apresentam dissonâncias em relação ao aporte teórico da $\mathrm{AD}$, de modo que a sua adoção acrítica se torna problemática. A gramática enquanto forma de saber coloca em questão uma noção de história que vai de encontro à da $\mathrm{AD}$, já que o que se coloca como uma espessura temporal a partir da qual o saber se projeta para o passado e para o futuro pressupõe uma certa linearidade histórica do conhecimento gramatical, isto é, a gramática é vista como um todo homogêneo no qual comparecem dizeres evidentes, cuja constituição, transmissão e recepção ao longo da história se dá de forma linear, literal e transparente. $\mathrm{E}$ isso ocorre, a despeito de se considerar, como vimos em Colombat, Fournier e Puech (2010), que o processo cumulativo de construção pressupõe também o esquecimento, já que se atribui ao historiador a capacidade de recuperar, para escrever a história da construção de dado conhecimento, aquilo que nele se mantém e aquilo que dele se esquece.

Ora, em AD, como sabemos, o que se entende por história, tal como postulou Paul Henry (2010), diz respeito à possibilidade de fazer sentido e, portanto, à produção de gestos de interpretação, os quais não se dão sem a filiação do sujeito à memória ou, melhor, a uma certa memória. Os sentidos são, pois, históricos porque têm memória, porque nela se inscrevem para significar, cabendo ao analista buscar compreender o processo de naturalização de 
determinados sentidos em detrimento de outros, processo esse que não é evidente, que não se dispõe linearmente na linha do tempo de modo a se estabelecer relações óbvias de causa e efeito. A Gramática, enquanto saber, não é homogênea, os sentidos que nela comparecem são historicamente construídos e se significam em relação a outros sentidos com os quais disputam espaço na forma material da gramática. Além disso, embora, na análise, possa ser descrito o processo de silenciamento de determinados sentidos, concebe-se desse lugar que o silenciamento pode acarretar o apagamento, de modo que, enquanto alguns sentidos continuam a produzir efeito sobre os sentidos hegemônicos, outros, por não serem considerados registráveis, podem ser condenados a habitar o silêncio, o que significa que não poderão ser recuperados.

Já o conceito de gramática enquanto instrumento linguístico é problemático tanto pela própria noção de instrumento como pela de hiperlíngua. No que tange à noção de instrumentos linguísticos, cabe pontuar que essa vem sendo mobilizada discursivamente por analistas brasileiros pelo menos desde Língua e cidadania (Orlandi e Guimarães, 1996, p.9), obra na qual se ressalta na apresentação a importância de considerá-los na sua relação com o "modo como a sociedade constrói elementos da sua identidade", ao mesmo tempo em que "se constitui historicamente". A noção de hiperlíngua, por seu turno, como explicaram Zoppi-Fontana e Diniz (2008, p.96), "implica uma concepção de comunicação, sujeito, história e língua bastante diferentes - por vezes, opostas - daquelas da Análise do Discurso". A nosso ver, o mesmo pode ser dito sobre a noção de instrumento. E isso porque a concepção de uma hiperlíngua que se projeta num instrumento linguístico pressupõe o estabelecimento em certos ambientes de relações de comunicação entre indivíduos baseadas em competências linguísticas. Essa concepção é conflitante em relação aos pressupostos teóricos da $\mathrm{AD}$, porque, em função da noção de interpretação, entende-se que há sempre comunicação e não comunicação. O equívoco é sempre possível, ele faz parte da língua, de modo que as mesmas palavras, sob condições de produção distintas, podem significar diferentemente. Isso significa que, em nossa perspectiva, uma vez que o equívoco é tomado como constitutivo, a suposta competência desenvolvida pelo instrumento não garante o estabelecimento de comunicação, mas produz a ilusão 
de.

Além disso, a noção de indivíduo dado a priori incutida no conceito de hiperlíngua e no de instrumento, já que se entende que por meio deste aquele pode ter a sua competência linguística desenvolvida, também é problemática do ponto de vista teórico. Em $\mathrm{AD}$, entende-se que os sujeitos se constituem/são constituídos nos/pelos processos discursivos, ou seja, a concepção de indivíduo presente na proposta de Auroux apaga, portanto, o processo histórico a partir do qual o sujeito, por meio do processo de identificação/subjetivação, se projeta no dizer ${ }^{22}$.

Por fim, outro ponto que é controvertido diz respeito à atuação do instrumento linguístico como ferramenta que possibilita o desenvolvimento da competência linguística do indivíduo. Tal concepção revela uma visão positivista do processo de ensinoaprendizagem, uma vez que, com o apagamento das condições históricas do sujeito, da gramática e das regras que nela comparecem, bem como do próprio processo de ensino-aprendizagem, o qual é visto como transparente e evidente, pressupõe-se que qualquer um, em qualquer lugar, pode, com uma gramática, ter acesso ao corpo de regras de uma língua e aprimorar a sua competência como falante, prolongando a sua fala natural.

Alinhados à discussão aqui desenvolvida, Baldini et al. (2018) asseveram que, apesar da relação de produtividade específica estabelecida no Brasil entre AD e HIL, a divergência entre esses dois domínios consiste no fato de não partirem dos mesmos pressupostos teóricos. Com base no pensamento althusseriano, os autores chamam atenção para o fato de que, assim como toda disciplina histórica afetada pela ideologia empirista, a HIL recobre-se de certo idealismo, dispensando a teoria (e, consequentemente, uma definição de objeto) ao, ilusoriamente, substituí-la pela metodologia. Tal fato, conforme os autores, implicaria ainda uma dupla ausência no corpo teórico da HIL, a saber: a da luta/divisão de classes e a do sujeito - noções essas fundamentais ao aporte da AD.

A leitura crítica dos conceitos de gramática que comparecem na obra de Auroux ([1992] 2009) demonstra, portanto, como e porque a articulação entre esses dois domínios de saber precisa ter como efeito a produção de deslizamentos de sentidos necessários à produção do gesto analítico do pesquisador. Assim sendo, entende-se que a 
inscrição no lugar de (des)encontro entre $\mathrm{AD}$ e $\mathrm{HIL}$, tal como formulado no Brasil, implica, assim como propõe Horta Nunes (2008, p.101), a inscrição do sujeito não no lugar do historiador, mas do analista-historiador, ou seja, do analista de discurso que, desse lugar, faz história das ideias linguísticas.

\section{Conclusão}

Neste artigo, busquei tecer algumas considerações iniciais sobre a historicização dos estudos em HIL na França e no Brasil. Para tanto, em meu gesto de leitura, considerei importante refletir, num primeiro momento, sobre o processo de institucionalização e de disciplinarização dessa teoria nas universidades brasileiras. Nesse sentido, destaquei dois pontos atinentes a esse processo que julgo importantes: o primeiro diz respeito à compreensão do seu processo de transferência da França para o Brasil e o segundo, intimamente ligado ao primeiro, ao funcionamento das articulações com outras teorias realizadas a partir do estabelecimento desse processo, fatos que, como visto, promoveram deslizamentos historicizados de sentidos em relação ao fazer instituído na França.

Num segundo momento, propus uma reflexão sobre a relação estabelecida entre HIL e HL, dada a opacidade que muitas vezes recobre as duas práticas. A partir da leitura de textos de referência dos dois domínios, busquei demonstrar que, embora haja de ambos os lugares um movimento de distanciamento de um certo fazer historiográfico, que, de cunho notadamente descritivo, não visa à explicação e à interpretação da produção do conhecimento linguístico, a tensão existente em ambos no que concerne aos termos história e historiografia, ao mesmo tempo que os aproxima, os afasta devido à concepção do objeto relacionado às práticas deles engendradas. A despeito disso, enquanto na França a distinção entre essas teorias não é uma questão que se coloque atualmente, havendo contradição entre os sentidos filiados a uma e a outra - contradição esta que se coloca em termos de uma heterogeneidade que lhes é constitutiva-, no Brasil, essa heterogeneidade, devido às articulações estabelecidas, ganha novos contornos, de modo que surgem diferentes práticas em HIL, as quais se distinguem da prática em HL.

Num terceiro momento, buscando descrever a materialidade da articulação entre $\mathrm{AD}$ e HIL, analisei o conceito de gramática tal como

Líng. e Instrum. Linguíst., Campinas, SP, n. 44, p.9-34, jul./dez. 2019 
definido na obra de Auroux. A partir dessa análise, foi possível perceber que, apesar de articulados, a inscrição do sujeito-analista nesse lugar não pressupõe a intercambialidade de conceitos, já que incorporações acríticas podem ser problemáticas do ponto de vista teórico. Com isso, filiando-me à reflexão tecida por Horta Nunes (2008), pude responder à segunda das três perguntas levantadas por mim ao longo deste artigo e chegar à conclusão de que trabalhar a partir da articulação entre AD e HIL é inscrever-se no lugar do analista-historiador, isto é, do analista de discurso que, calcado no aporte teórico-metodológico da $\mathrm{AD}$, tem a história das ideias linguísticas, procedidos os devidos deslocamentos, como objeto e fim.

\section{Referências bibliográficas}

ALTMAN, C. (2012). "História, estórias e Historiografia da linguística brasileira”. In: Todas as Letras, v.14, n.1, p.14-37.

AUROUX, S. (2009). A revolução tecnológica da gramatização (1992). Trad. Eni P. Orlandi. Campinas, SP: Editora da UNICAMP. $2^{\mathrm{a}}$. ed.

. (1988). "Pour une histoire des idées linguistiques". In:

Revue de Synthese: IV' S. n.3-4, p.429-441.

BALDINI, L. et. al. (2018). "História das ideias linguísticas e análise do discurso: o corte epistemológico". In: Fragmentum n.52. Santa Maria: Editora Programa de Pós-Graduação em Letras, UFSM, p.1533.

COLOMBAT, B.; FOURNIER, J.M et PUECH, C. (2010). Histoire des idées sur le langage et les langues. Paris: Kliincksieck.

FERREIRA, A. C. F. (2018). "A Análise de Discurso e a constituição de uma História das Ideias Linguísticas do Brasil”. In: Fragmentum n.Especial. Santa Maria: Editora Programa de Pós-Graduação em Letras, UFSM, p.17-47.

HENRY, P. (2010). “A História não Existe?”. In: Gestos de Leitura: da História no Discurso. Campinas: Editora da Unicamp, p.23-48. HORTA NUNES, J. (2008). "Uma articulação da análise de discurso com a história das ideias linguísticas". In: SCHERER, Amanda E.; PETRI, V. (Orgs.). Língua, Sujeito e História. v.18. n.37. Santa Maria, UFSM: Programa de pós-graduação em Letras, p.107-133. 
KOERNER, K. (1978). "Four types of history writing in linguistics". In: Toward a historiography of linguistics selected essays. Amsterdam: Jonh Benjamins B.V., p.55-69.

(1996). "Questões que persistem em historiografia linguística”. In: Revista Anpoll, n.2, p.45-70.

(2014). "História da linguística". In: Revista Confluência. n.46. Rio de Janeiro, p.9-22.

KUHN, T. (1983). La strutucture des révolutions scientifiques (19621970). Paris: Flammarion.

MARIANI, B. (1998). O PCB e a imprensa: os comunistas no imaginário dos jornais (1922-1989). Rio de Janeiro: Revan; Campinas, SP: UNICAMP.

MITTMANN, S. (2010). "Heterogeneidade constitutiva, contradição histórica e sintaxe". In: Revista do Programa de Pós-Graduação em Letras da Universidade de Passo Fundo, v.6, n.1, p.85-101.

ORLANDI, E. (2003). "Vão surgindo sentidos". In: Discurso Fundador. Campinas, SP: Pontes. $3^{\mathrm{a}}$ ed.

(org.). (2001). História das idéias linguísticas: Construção do saber metalinguístico e a constituição da língua nacional. Campinas, SP: Pontes e Cáceres, MT: Unemat Editora.

. (2005). "A Análise de Discurso em suas diferentes tradições intelectuais: O Brasil”. In: I Seminário de Estudos em Análise do Discurso (SEAD). Porto Alegre, Anais. Porto Alegre: UFRGS. Disponível em:

<http://www.ufrgs.br/analisedodiscurso/anaisdosead/1SEAD/Confere ncias/EniOrlandi.pdf>. Acesso em: 20 de junho de 2015.

ORLANDI, E.; GUIMARÃES, E. (1996). Lingua e cidadania: $O$ português no Brasil. Campinas, SP: Pontes.

. (2002). Institucionalização dos estudos da linguagem: a disciplinarização das ideias linguísticas. Campinas, SP: Pontes.

PÊCHEUX, M.; FUCHS, C. (2010). "A propósito da análise automática do discurso: atualização e perspectivas (1975)". In: GADET, F.; HAK, T. (Org.). Por uma análise automática do discurso: uma introdução à obra de Michel Pêcheux. Campinas: Editora da UNICAMP, p.163-252.

PÊCHEUX, M. (2006). Discurso: estrutura e acontecimento. Campinas, SP: Pontes. 
PUECH, C. (Org.). (2006). "Histoire des idées linguistiques et Horizons de rétrospection". Vol.1. In: Histoire Epistémologie Langage, t.XXVIII 1.

SCHERER, A.E.; SOUSA, L.M.A.; MEDEIROS, V.; PETRI, V. (2014). "O lugar dos estudos franceses na constituição de uma memória da Análise de Discurso no Brasil". In: Letras, Santa Maria, v.24, n.48, p.13-28.

SWIGGERS, P. (1998). "Filologia E Lingüística: enlace, divórcio, reconciliação". In: Filologia e Lingüística Portuguesa, n.2, p.5-18.

(1996). "Jean-François Thurot". In:

STAMMERJOHANN, H. (Ed.). Lexicon grammaticorum: Who's who in the history of world linguistics. Tübingen: Max Niemeyer Verlag, p.918-919.

. (2010). "História e historiografia da linguística: status, modelos e classificações". In: Revista Eutomia, Ano III, v. 2.

ZOPPI-FONTANA, M. G.; DINIZ, L. (2008). "Declinando a língua pelas injunções do mercado: institucionalização do português língua estrangeira (PLE)". In: Estudos Lingüísticos, São Paulo, 37 (3), p.89119.

ZOPPI-FONTANA, G. (2013). "Presentación: Análisis del discurso en Brasil: teoría y práctica”. In: Signo y Seña, n. 24, p.3-9.

Palavras-chave: História das Ideias Linguísticas, Institucionalização, Disciplinarização.

Keywords: History of the Linguistic Ideas, Institutionalization, Disciplinarization.

\section{Notas}

* Graduada em Letras (Português/Literaturas) pela Universidade do Estado do Rio de Janeiro (UERJ), Mestre em Língua Portuguesa pela mesma instituição e Doutora em Estudos da Linguagem pela Universidade Federal Fluminense (UFF).

2 Evanildo Bechara e a(s) moderna(s) gramática(s) portuguesa(s): autoria, (re)produção, (re)formulação e circulação de dizeres sobre a língua no/do Brasil no século XX (UFF, 2016). Tese desenvolvida sob a orientação da Profa. Dra. Vanise Medeiros.

${ }^{3}$ Dialogo aqui com Nunes (2018).

Líng. e Instrum. Linguíst., Campinas, SP, n. 44, p.9-34, jul./dez. 2019 


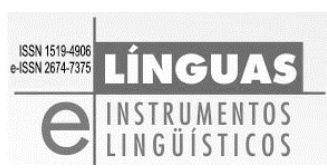

${ }^{4}$ Cabe aqui destacar que tomar a contradição como objeto de análise significa concebê-la como princípio de historicidade de todo e qualquer discurso. Os discursos são, conforme Mittmann (2010, p.85), constitutivamente contraditórios porque são constituídos "pela multiplicidade de fragmentos, de partículas disformes de discursos e, também, de saberes dispersos", os quais estão filiados a diferentes posições-sujeito.

5 Para mais estudos sobre a instituição da $\mathrm{AD}$ na França e no Brasil, ver Orlandi (2005), Baldini e Zoppi-Fontana (2013), entre outros.

${ }^{6}$ Criado por Jean-Claude Chevalier em 1984 e dirigido pelo próprio até 1992. Desde 2009, encontra-se sob a tutela do CNRS (Centre National de la Recherche Scientifique), da Université Paris Diderot (Paris 7) e da Université Sorbonne Nouvelle (Paris 3). Atualmente, é dirigido por Anne Grondeux e Jean-Marie Founier. Endereço na internet: $<\mathrm{http}: /$ htl.linguist.univ-paris-diderot.fr/accueil $>$.

${ }^{7}$ Esse projeto teve como resultado a publicação, em 1989, sob sua organização, de uma obra homônima de cerca de mil páginas divididas em três tomos.

${ }^{8}$ Alguns dos resultados desse projeto foram publicados, em 1996, no livro Língua e cidadania: O português no Brasil, organizado por Eni Orlandi e Eduardo Guimarães e, em 2001, no livro História das ideias linguísticas, organizado por Eni Orlandi (Cf. Referências).

9 Cf. Histórico do projeto História das Ideias Linguísticas. In: <https://www.unicamp.br/iel/hil/historico.html>. Acesso em: 16/3/2019.

${ }^{10}$ Alguns dos resultados desse segundo projeto foram publicados em 2002 no livro Institucionalização dos estudos da linguagem: a disciplinarização das ideias linguísticas, organizado por Eni Orlandi e Eduardo Guimarães (Cf. Referências).

${ }^{11}$ Mobilizamos aqui a noção de transferência desenvolvida por Orlandi (op. cit.) para refletir sobre a constituição de um saber sobre a língua no Brasil a partir do início da colonização. Tal como propusera a autora, essa noção distingue-se da de transporte (da língua portuguesa de Portugal para o Brasil), no sentido em que naquela, diferentemente do que ocorre nesta, observa-se o trabalho da memória local e, por conseguinte, a produção de deslizamentos historicizados de sentidos.

${ }^{12}$ Filiados à articulação estabelecida a partir dos trabalhos de Orlandi, citem-se ainda trabalhos desenvolvidos nos laboratórios Corpus (UFSM), LAS (UFF), E-1@dis (USP/Ribeirão Preto), entre outros.

13 Cf. também, por exemplo, os estudos desenvolvidos sob coordenação de Dieli Vesaro Palma e Neusa M. O. B. Bastos, no Instituto de Pesquisas Linguísticas (IPPUC-SP), e por Ricardo Cavaliere e Leonardo Ferreira Kaltner, na Universidade Federal Fluminense (UFF).

${ }^{14} \mathrm{O}$ discurso fundador, como nos explica Orlandi (2003), é uma ruptura que instaura uma nova ordem de sentidos, ou seja, "ele cria uma nova tradição, ele ressignifica o que veio antes e institui aí uma memória outra" (ibid., p.13), servindo-se, para tanto, dos sentidos precedentes, do já-dito, para instalar o "novo" e, em seguida, desautorizá-los. E é nisso que, segundo propõe a autora, reside a sua singularidade. $\mathrm{O}$ discurso fundador se apropria do efeito de reconhecimento que estabelece com a memória a que se filia para ressignificá-la e produzir o diferente, instalando uma nova filiação e produzindo sua própria memória.

15 Nesta categoria se inclui, conforme Puech (2006, p.17), por exemplo, o capítulo

Líng. e Instrum. Linguíst., Campinas, SP, n. 44, p.9-34, jul./dez. 2019 
sobre história da linguística escrito por Bally et Sechehay que introduz o Curso de Linguística Geral. Segundo o autor, nele se busca «avant tout à installer le 'nouveau' (la linguistique est une science historique, le point de vue 'grammatical' est définitivement dépassé, la diachronie n'est pas l'histoire...) comme socle d'une discipline qu'on ne peut réduire à son passé et qui prépare à une véritable conversion de point de vue». [Tradução minha: antes de tudo instalar o novo (a linguística é uma ciência histórica, o ponto de vista gramatical é definitivamente ultrapassado, a diacronia não é a história) como base de uma disciplina que não pode se reduzir ao seu passado e que se prepara para uma verdadeira conversão de ponto de vista].

${ }^{16}$ A estas Altman (2012) também faz referência, incluindo dentre elas a História da linguística, de Mattoso Câmara, cuja primeira edição, em inglês, data de 1962 e, em português, de 1975, primeira e única obra do gênero publicada por um brasileiro, segundo a autora, pelo menos até os anos de 1980.

17 Tradução minha: "um deslocamento da rede conceitual através da qual os homens da ciência veem o mundo".

18 Tradução minha: "criar igualmente as condições de uma reflexão profunda sobre o modo de ser particular dos conhecimentos sobre as ciências da linguagem, sabendo que eles podem contraditoriamente ser objeto do esquecimento e da cumulação".

19 Tradução minha: "modelos historiográficos mais ou menos complementares ou mais ou menos concorrentes".

${ }^{20}$ É interessante observar que, embora empregue o termo historiografia para designar a sua prática, Puech (op. cit.) não se significa como historiógrafo, mas como historiador.

${ }^{21}$ Remeto-me aqui à Ferreira (2018, p.28), que, evidenciando que as pesquisas em HIL têm contribuído fortemente não apenas para uma descolonização linguística, mas também científica, pontua que "podemos dizer que não estamos mais apenas no domínio da História das Ideias Linguísticas no Brasil, mas no domínio da História das Ideias Linguísticas do Brasil" [itálico da autora].

${ }^{22}$ Zoppi-Fontana e Diniz (op. cit.) elencam ainda outros pontos que demonstram a inadequação teórica do conceito de hiperlíngua para as pesquisas em AD. Porém, para o propósito deste artigo, julgamos serem suficientes os pontos aqui expostos.

Líng. e Instrum. Linguíst., Campinas, SP, n. 44, p.9-34, jul./dez. 2019 